\title{
RELATIONSHIP BETWEEN AIR FLOW INDICES AND LOCAL RAINFALL IN KYUSHU, JAPAN
}

\author{
Jonas OLSSON ${ }^{1}$, Cintia B. UVO ${ }^{2}$ and Kenji JINNO \\ ${ }^{1}$ Member of JSCE, Ph.D. Eng., Inst. of Environmental Systems, Kyushu University (6-10-1 Hakozaki, Higashi-ku, Fukuoka 812- \\ 8581, Japan) \\ ${ }^{2}$ Ph.D. Eng., Dept. of Water Resources Engineering, Lund University (Box 118, SE-221 00 Lund, Sweden) \\ ${ }^{3}$ Member of JSCE, Dr. of Eng., Professor, Inst. of Environmental Systems, Kyushu University (6-10-1 Hakozaki, Higashi-ku, \\ Fukuoka 812-8581, Japan)
}

\begin{abstract}
Downscaling of large-scale atmospheric circulation characteristics to estimate local hydrometeorological processes is important, e.g., for assessing the local impact of a possible future climate change. In the present study, this possibility was investigated for Kyushu Island, Japan. Six months of 12-h values of two large-scale air flow indices, wind flow $f$ and vorticity $z$, estimated using different spatial resolutions, were correlated with rainfall observed at 128 stations on Kyushu. For both $f$ and $z$, the correlations increased with increasing resolution. For the highest resolution, the mean correlation for $f$ was 0.198 and the maximum correlation 0.306 . For $z$, the corresponding values were 0.482 and 0.764 . Firstly, the results show that vorticity has a potential to be used as a predictor in downscaling of GCM output to hydrologically relevant scales, as well as a variable in rainfall time series modeling. Secondly, they indicate that the output of GCM models need to have a spatial resolution of at least $2.5^{\circ} \times 2.5^{\circ}$ in order for meaningful statistical downscaling to be feasible.
\end{abstract}

Key Words: Atmospheric circulation, wind flow, vorticity, rainfall, downscaling

\section{INTRODUCTION}

So-called downscaling of atmospheric circulation characteristics in order to estimate hydrometeorological variables on a local or regional scale is an active field of research. Generally, the aim is to find relationships between variables related to large-scale atmospheric circulation and variables representing the local or regional hydroclimate. Typical examples of the former are surface pressure, geopotential height, winds or geostrophic flow strength, and vorticity; typical examples of the latter are precipitation and temperature.

The justifications put forward for investigating the above relationships have been several. First, from a general point of view, gain an increased understanding of the large-scale forcing on local processes. Assessments of how much of these processes variability that can be attributed to large-scale features and how much that is related to local modifications and microclimatology indicates the possibilities of forecasting of local processes. This general issue has been studied at least since the 1960 's ${ }^{1)}$, and the studies have generally concerned monthly precipitation where local or regional amounts have been related to atmospheric variables. More recently, Walsh et al. (1982) and Klein and Bloom (1987) established coherent regions of monthly precipitation in the USA and investigated the relationship with atmospheric circulation ${ }^{2), 3}$. They found significant correlations of 0.3-0.7 between on one hand the monthly precipitation and on the other hand geopotential height, geostrophic wind, and vorticity on the $700 \mathrm{mb}$ level. The correlation strengths exhibited strong geographical and seasonal dependences. Weare and Hoeschele (1983) and Cayan and Roads (1984) found similar results in similar investigations of monthly rainfall on the west coast of $\mathrm{USA}^{4,5)}$.

Second, more recent interest in the issue is largely due to the question of climate change. Future climate is simulated by general circulation models (GCM), often under an assumption of enhanced levels of greenhouse gases. However, the spatial resolution of GCM output is generally too coarse to draw any conclusions about changes in the local climate, which makes it difficult to assess the local and regional 
impact of climate change on water resources. Therefore there is a need to establish functional links between atmospheric circulation on the scale resolvable by GCM's and the local-scale variability of hydrometeorological processes. A number of investigations have analyzed downscaling from this point of view, typically using a monthly time resolution. Kim et al. (1984) investigated the relationships between local and large-scale values (at a single GCM grid point) of monthly climatic variables in the state of Oregon, USA $^{6)}$. Karl et al. (1990) developed a general methodology to relate GCM grid-point freeatmosphere statistics to local surface observations $^{7}$. Wigley et al. (1990) used essentially the same data as Kim et al. (1984) to relate pressure and pressure gradients at sea level and $700 \mathrm{mb}$, respectively, to local temperature and precipitation on a monthly basis ${ }^{8}$. Von Storch et al. (1993) related monthly variation patterns of winter precipitation on the Iberian peninsula to large- patterns scale of sea level pressure in the North Atlantic ${ }^{9}$. Some recent investigations have used a higher temporal resolution, notably Wilby et al. (1998) who investigated the relationships between various hydrometeorological variables and airflow indices (vorticity, flow strength and direction) on a daily basis in Nagano, Japan ${ }^{10)}$. Particularly, a nonlinear relationship between vorticity and rainfall probability and amount was found ${ }^{10)}$. An important contribution was made by Kidson and Thompson (1998) who showed that statistical downscaling performed similarly to regional (mesoscale) modeling for transfering GCM output for New Zealand to local scales on a daily basis ${ }^{11)}$.

Third, the relationships have been studied from the point of view of rainfall time series modeling. Including information about the largescale atmospheric patterns may be a physically based way to improve stochastic models, as well as a means to model the temporal rainfall process under different climate scenarios ${ }^{12), 13), 14)}$.

From the above literature review it is obvious that large-scale atmospheric circulation characteristics are potentially strongly linked to the local and regional hydroclimate, and may be used to infer rainfall and other hydrometeorological variables at specific locations. However, the investigations are as yet few and many open issues remain. One particular issue is the relationship between the temporal resolution and the extension and resolution of the spatial area. Concerning the time scale employed, as mentioned above, this has usually been monthly, but recent studies have shown that the methodology may be useful even on a daily time scale basis $^{10), 11)}$. However, for such small time scales the coarse spatial grids used for monthly time scales (typically $5^{\circ} \times 5^{\circ}$ or coarser), are hardly relevant since the day-to-day variabilities are governed by mesoscale phenomena that are not captured properly in $5^{\circ} \times 5^{\circ}$ grids. Thus, there is a need to investigate which spatial resolution, e.g., in GCM output, that is required for accurate assessment of the local hydrometeorological variability on a daily basis. Such studies have not been previously made, to the authors' knowledge, and thus this issue is the main focus of the present paper.

In the light of this, the aim of the present paper is twofold. Generally, to investigate the possibility of downscaling of atmospheric circulation characteristics to local rainfall in Kyushu Island, Japan, particularly at a high temporal resolution. Specifically, to investigate the influcnce of the spatial ared and resolution in this process.

\section{MATERIAL AND METHODOLOGY}

The atmospheric data consist of grid point value (GPV) meteorological data used by Japan Meteorological Agency as input to the Japan Spectral Model. Geopotential height, temperature, dew point temperature, and wind speeds are available at 21 vertical levels. The total area covered is shown in Fig. 1. The data are obtained by radiosondes at a number of locations within and outside Japan and then transformed to a $20 \times 20 \mathrm{~km}$ grid by optimal interpolation ${ }^{15}$. Data collection is made twice a day at $00 \mathrm{Z}$ and $12 \mathrm{Z}$ and since the time period available for the present investigation is 6 months (AprilSeptember 1996), the total number of time instants is 366.

From the GPV data, numerical values of wind flow $(f)$ and vorticity $(z)$ for each time instant was obtained using the simplified scheme developed by Jones et al. $(1993)^{16)}$ and used by, e.g., Wilby et al. $(1998)^{10)}$. In the present study, sea level pressure data from square sub-areas of different sizes were extracted from the data base and the original data in each square was transformed into $3 \times 3$ grids by simple averaging. From these averaged sea level pressures $f$ and $z$ were obtained (for details of the latter procedure, see Jones et al. $\left.(1993)^{16)}\right)$. We used three square areas of different sizes (see Fig. 1): $720 \times 720 \mathrm{~km}\left(5.2 \times 10^{5}\right.$ $\left.\mathrm{km}^{2}\right), 1440 \times 1440 \mathrm{~km}\left(2.1 \times 10^{6} \mathrm{~km}^{2}\right)$, and $2160 \times 2160$ $\mathrm{km}\left(4.7 \times 10^{6} \mathrm{~km}^{2}\right)$, and thus a total of six time series were produced. A $3 \times 3$ grid in these areas corresponds to a latitude-longitude resolution of approximately 


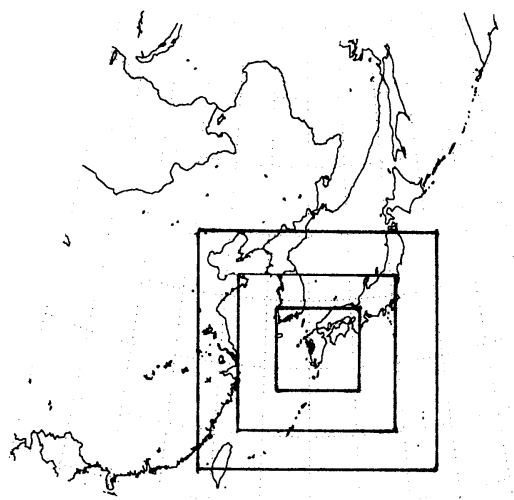

Fig.1 Study area. The three square areas are the areas used in the calculation of $f$ and $z$ indices.

$2.2^{\circ} \times 2.6^{\circ}, 4.3^{\circ} \times 5.2^{\circ}$, and $6.4^{\circ} \times 7.8^{\circ}$, respectively, and the middle square thus roughly agrees with the resolution typically used in atmospheric downscaling.

Local rainfall data were available from the Japanese national meteorological network (AMeDAS). In this network, rainfall is measured on an hourly basis. For the present study the 1hour values were accumulated into 12 -hour values centered at $00 \mathrm{Z}$ and $12 \mathrm{Z}$ to coincide with the GPV data. The number of AMeDAS stations in Kyushu Island is more than 150 , but some were discarded due to periods with missing data. The number of stations used in the present study is therefore 128.

The strengths of the relationships between the time series of air flow indices obtained using different areas, and on the time series of local rainfall were quantified in terms of the standard correlation coefficient $(r)$. Since the number of data in each time series was 366 , all correlation coefficients larger than 0.15 are significant at a $99.9 \%$ level. The correlation coefficients for the stations were spatially interpolated (linear interpolation) and correlation isolines covering Kyushu Island were plotted.

\section{RESULTS AND DISCUSSION}

Fig. 2a-c show the result for wind flow. The relationship between $f$ calculated from the large square and local rainfall is very weak with $r \approx 0.1$ (Fig. 2a). For $f$ from the middle square, the result slightly improves and small areas of significant correlations are present with a maximum of $r \approx 0.25$ (Fig. 2c). For $f$ from the small square, $r$ reaches 0.306 in the mountainous central part of Kyushu Island, but the overall relationship is still weak (Fig. 2c).
Fig. 3a-c show the result for vorticity. The correlations obtained using $z$ from the large square displays a large area of $r>0.4$ extending from the central island towards north-east (Fig. 3a). This area almost 0.1 higher, reaching 0.6 in the central island (Fig. 3b). For the small square values of $r$ in the north-western and central to north-eastern Kyushu are further increased by 0.1 or more up to a maximum value of 0.764 (Fig. 3c). For other areas, however, $r$ is similar to the middle square results.

Table 1 Mean and maximum correlations between precipitation and wind flow and vorticity indices from the three square areas.

\begin{tabular}{|l|l|l|l|l|}
\hline Square & f, mean & f, max & z, mean & z, max \\
\hline \hline small & 0.198 & 0.306 & 0.482 & 0.764 \\
\hline middle & 0.121 & 0.248 & 0.434 & 0.596 \\
\hline large & 0.097 & 0.188 & 0.349 & 0.465 \\
\hline
\end{tabular}

In Table 1, mean and maximum correlations between precipitation and wind flow and vorticity indices from the three square areas are shown.

It is clear that wind flow has a limited potential to act as atmospheric downscaling predictor in the present region, whereas vorticity appears to exert a strong forcing on the local rainfall process. For both $f$ and $z$, the correlations showed a clear increase with decreasing size of the area. As expected, the spatial resolution typically used for downscaling $\left(5^{\circ} \times 5^{\circ}\right.$ or lower) does not provide the level of detail relevant for downscaling at daily or smaller time scales. However, the results from using $f$ and $z$ from the small square shows that correlations of a magnitude required for atmospheric downscaling at daily or smaller time scales may be obtained using higher a spatial resolution.

These results can be compared with the results of Wilby et al. (1998) who, among other things, investigated the relationship between airflow indices and local rainfall in Nagano, Japan ${ }^{10)}$. For a 17-year period, they correlated $f$ and $z$ from a $2.5^{\circ} \times 3.75^{\circ}$ grid to daily average rainfall from five stations. For $f$, they found a mean $r$ of 0.097 , thus identical to the value obtained for the large square in the present study. For $z$, they found a mean $r$ of 0.462 , which is in between the value obtained for the middle and small square, respectively. The fact that the grid size and resolution used by Wilby et al. $(1998)^{10)}$ is also in between the resolution of the middle and small squares indicates that the relationship between the area used to estimate the vorticity and the strength of the correlation between vorticity and rainfall may not be locally specific but applicable also to other regions. 

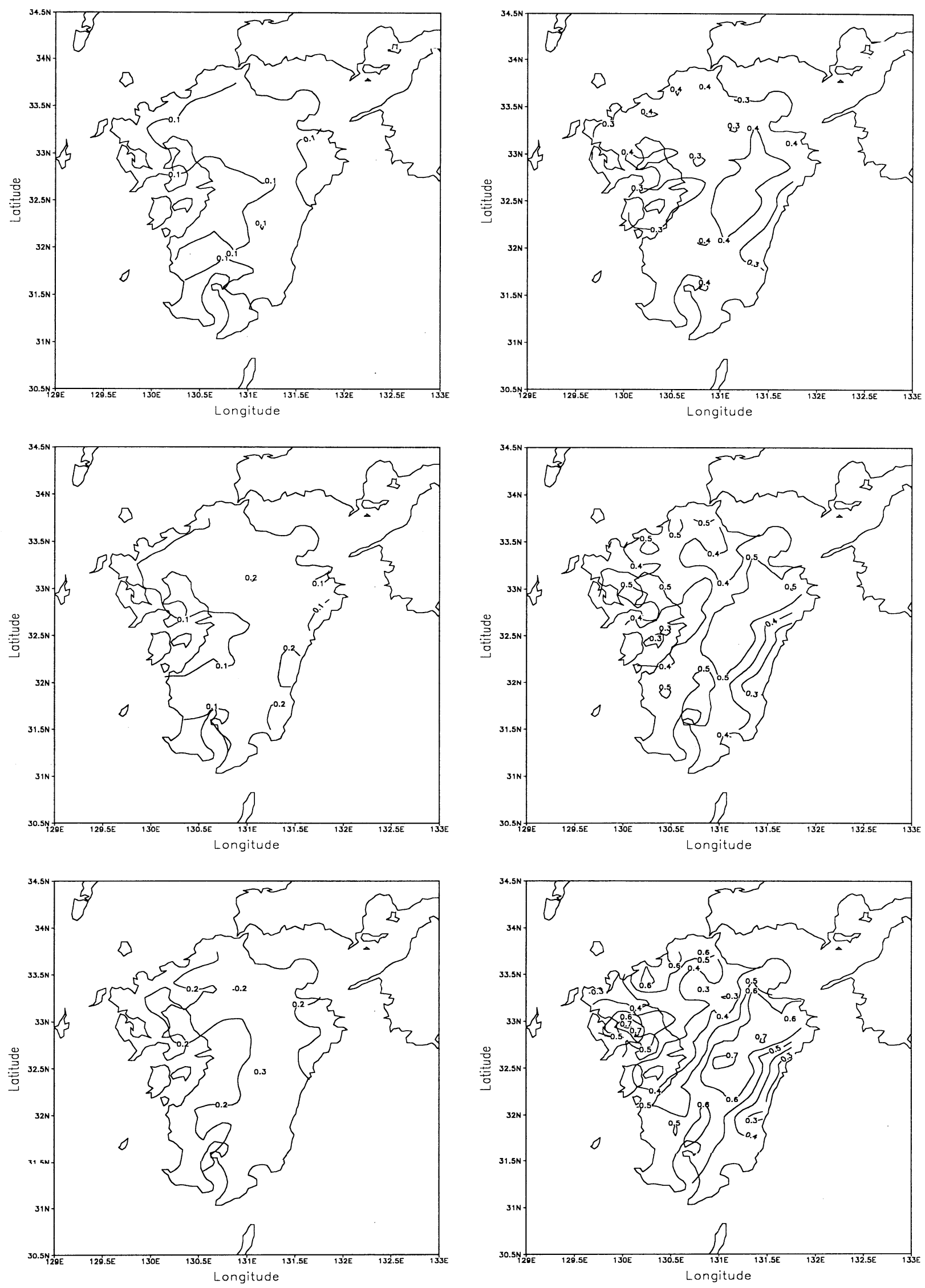

Fig.2 Correlation field between rainfall and wind flow $f$ calculated from large area, middle area and small area, from top to bottom

Fig.3 Correlation field between rainfall and vorticity $z$ calculated from large area, middle area and small area, from top to bottom. 


\section{SUMMARY AND CONCLUSIONS}

The relationship between atmospheric circulation parameters and local rainfall in Kyushu Island, Japan, was investigated by correlating six month long 12-h time series of wind flow $(f)$ and vorticity $(z)$ to corresponding rainfall time series observed at 128 stations. For the square area used in the indices calculation, three spatial extensions were used corresponding to a latitude-longitude resolution of approximately $2.2^{\circ} \times 2.6^{\circ}, \quad 4.3^{\circ} \times 5.2^{\circ}, \quad$ and $6.4^{\circ} \times 7.8^{\circ}$. For both $f$ and $z$, the correlations clearly increased with increasing resolution. For the highest resolution (smallest square), the mean correlation for $f$ was 0.198 and the maximum correlation 0.306 . For $z$, the corresponding values were 0.482 and 0.764 . The correlation patterns, particularly for $z$, displayed clear topographical effects.

Firstly, it is evident that vorticity at a spatial scale of about $5 \times 10^{5} \mathrm{~km}^{2}$ constitutes a strong forcing mechanism on the local rainfall process on Kyushu Island, Japan. Thus, vorticity has a potential to be used as a predictor in downscaling of GCM output to hydrologically relevant scales, as well as a variable in rainfall time series modeling. Secondly, the success of statistical downscaling at daily time scales is critically dependent on the spatial resolution with which the atmospheric variables are observed. The present study indicated that data at resolutions below $5^{\circ} \times 5^{\circ}$ do not contain the signals required for meaningful daily downscaling, but that a resolution of at least $2.5^{\circ} \times 2.5^{\circ}$ is required. This should be taken into account in the development of the next generation of global circulation models.

However, additional research is needed to further establish the above results. One obvious course of action is to study the applicability of areas even smaller than the small square used here in the vorticity calculation. Another issue is how a temporal lagging of the vorticity relative to the rainfall will affect the results. Finally, since a non-linear relationship between large-scale circulation variables (e.g., vorticity) and local rainfall has been found in some studies ${ }^{10), 14), 17)}$, the application of nonlinear statistical techniques (e.g., neural networks) is likely to further improve the correlations.

ACKNOWLEDGEMENT: Jonas Olsson is at Institute of Environmental Systems, Kyushu
University, under a scholarship funded by the European Union and the Japan Society for the Promotion of Science. Cintia B. Uvo is on leave from the Department of Water Resources Engineering, Lund University, at the Institute of Environmental Systems, Kyushu University, under a grant from the Nils Hörjel foundation. The figures in this manuscript were developed using GrADS (Gridded Analysis and Display System) developed at the University of Maryland. The reviewers are gratefully acknowledged for providing helpful comments.

\section{REFERENCES}

1) Klein, W. H.: Specification of precipitation from the 700millibar circulation, Mon. Wea. Rev., Vol.91, pp.527-536, 1963.

2) Walsh, J. E., Richman, M. B. and Allen, D. W.: Spatial coherence of monthly precipitation in the United States, Mon. Wea. Rev., Vol.110, pp.272-286, 1982.

3) Klein, W. H. and Bloom, H.J.: Specification of monthly precipitation over the United States from the surrounding 700 mb height field, Mon. Wea. Rev., Vol.115, pp.2118-2132, 1987.

4) Weare, B. C. and Hoeschele, M. A.: Specification of monthly precipitation in the Western United States from monthly mean circulation, J. Climate Appl. Meteorol., Vol.22, pp.1000-1007, 1983.

5) Cayan, D. R. and Roads, J. O.: Local relationship between United States west coast precipitation and monthly mean circulation parameters, Mon. Wea. Rev., Vol.112, pp.1276$1282,1984$.

6) Kim, J.-W., Chang, J.-T., Baker, N. L., Wilks, D. S. and Gates, W. L.: The statistical problem of climate inversion: determination of the relationship between local and large-scale climate, Mon. Wea. Rev., Vol.112, pp.2069-2077, 1984.

7) Karl., T. R., Wang, W.-C., Schlesinger, M. E., Knight, R. W. and Portman, D.: A method of relating general circulation model simulated climate to the observed local climate. Part I: seasonal statistics, J. Climate, Vol.3, pp.1053-1079, 1990.

8) Wigley, T. M. L., Jonas, P. D., Briffa, K. R. and Smith, G.: Obtaining sub-grid-scale information from coarse resolution general circulation model output, J. Geophys. Res., Vol.95, pp.1943-1953, 1990.

9) von Storch, H., Zorita, E. and Cubasch, U.: Downscaling of global climate change estimates to regional scales: an application to Iberian rainfall in wintertime, J. Climate., Vol.6, pp.1161-1171, 1993.

10) Wilby, R .L., Hassan, H. and Hanaki, K.: Statistical downscaling of hydrometeorological variables using general circulation model output, J. Hydrol., Vol.205, pp.1-19, 1998.

11) Kidson, J. W. and Thompson, C. S.: A comparison of statistical and model-based downscaling techniques for estimating local climate variability, J. Climate, Vol.11, pp.735-753, 1998.

12) Hay, L. E., McCabe, G. J., Wolock, D. M. and Ayers, M.A.: Simulation of precipitation by weather type analysis, Water Resour. Res., Vol.27, pp.493-501, 1991.

13) Bardossy, A. and Plate, E.: Space-time model for daily rainfall using atmospheric circulation patterns, Water Resour. Res., Vol.28, pp.1247-1259, 1992.

14) Hewitson, B.C. and Crane, R.G.: Large-scale atmospheric controls on local precipitation in tropical Mexico, Geophys. Res. Let., Vol.19, pp.1835-1838, 1992. 
15) Gandin, L. S.: Objective analysis of meteorological fields, Hydrometeoizdat, pp.236, Leningrad, 1963.

16) Jones, P. D., Hulme, M. and Briffa, K. R.: A comparison of Lamb circulation types with an objective classification scheme, Int. J. Climatol., Vol.13, pp.655-663, 1993.
17) Wilby, R., Conway, D. and Jones, P.: GCM downscaling using air flow indices, Proc. of Int. Conf. On Water Resour. \& Environ. Res., Kyoto, Japan, Oct 29-31, pp.325-332, 1996.

(Received September 30, 1998) 